
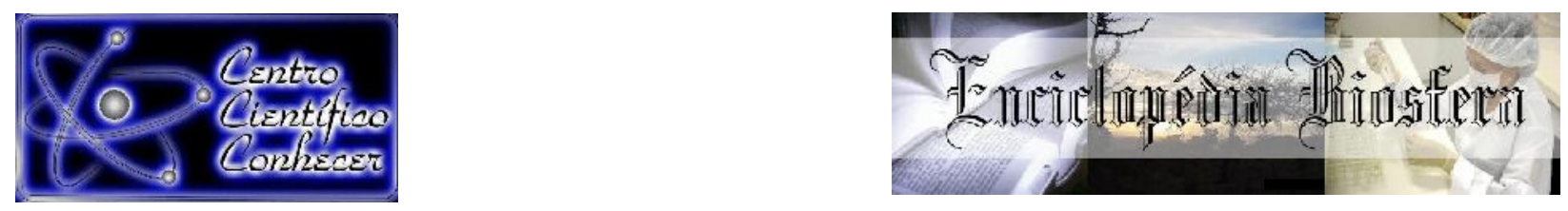

\title{
A TEORIA DA DERROTABILIDADE DA NORMA JURÍDICA E O PRINCÍPIO DA DIGNIDADE DA PESSOA HUMANA
}

Marcelo Vieira Camargo ${ }^{1}$

${ }^{1}$ Mestrando em Direito pela EPD - Escola Paulista de Direito. Pós-Graduado pela PUC/SP em Processo Civil em Módulos, Pós-Graduado em Direito Empresarial pela PUC/PR, Formação de Mediador e Conciliador pelo TASP, Conciliador e Mediador

do Tribunal de Justiça de São Paulo, Advogado.

E-mail: mvcamargoadvocacia@gmail.com

Recebido em: 15/05/2021 - Aprovado em: 15/06/2021 - Publicado em: 30/06/2021 DOI: 10.18677/EnciBio_2021B5

\section{RESUMO}

Este estudo teve por objetivo geral analisar a Teoria da Derrotabilidade das Normas, tendo como base o estudo da hermenêutica, sua evolução e possibilidade de aplicação dentro do cenário jurídico brasileiro, isto é, dando ênfase à linguagem. De acordo com seu patrono Herbert L. A. Hart, as normas jurídicas podem deixar de ser aplicadas em determinados casos concretos, considerando as relações sociais e a impossibilidade de consolidação, sendo imprescindível analisar suas principais nuances e sua compatibilidade com o Direito Brasileiro, considerando a fundamentação teórica e suas condições. Realizou-se pesquisa bibliográfica, partindo de uma visão geral a uma específica, observando os principais pontos concernentes ao tema proposto, bem como a importância do tema, suas características, condições de aplicabilidade e relação íntima com a hermenêutica jurídica. Concluiu-se pela possibilidade de aplicação no ordenamento brasileiro, sendo reconhecido como instrumento hábil e capaz para resolução de inúmeros casos em que ocorrem injustiças aplicando leis que tem por objeto relações sociais diversas, resguardando o indivíduo.

PALAVRAS-CHAVE: Derrotabilidade das Normas; Hermenêutica; Norma Jurídica.

\section{THE THEORY OF DERROTABILITY OF THE LEGAL RULE AND THE PRINCIPLE OF DIGNITY OF THE HUMAN PERSON}

\begin{abstract}
This study had as its general objective the analysis of the Defeatability of Norms Theory, based on the study of hermeneutics, its evolution and possibility of application within the Brazilian legal scenario, that is, emphasizing language. According to his patron Herbert LA Hart, legal norms may not be applied in certain concrete cases, considering the social relations and the impossibility of consolidation, being essential to analyze their main nuances and their compatibility with Brazilian Law, considering the theoretical and your conditions. A bibliographical research was carried out, starting from an overview to a specific one, observing the main points concerning the proposed theme, as well as the importance of the theme, its
\end{abstract}


characteristics, conditions of applicability and intimate relationship with legal hermeneutics. It was concluded by the possibility of application in the Brazilian law, being recognized as a skillful and capable instrument for solving cases in which injustices occur, applying laws that have different social relations, protecting the individual.

KEYWORDS: Defeatability of Norms; Legal Norm; Hermeneutics.

\section{INTRODUÇÃO}

Inegável a importância do tema abordado na presente pesquisa, não sendo possível, contudo, exaurir o assunto. $O$ trabalho apresentado busca uma análise a respeito do tema, analisando pontos essenciais para a compreensão da pesquisa. De uma forma geral, por derrotabilidade da norma jurídica, entende-se a possibilidade que uma norma tem que ser afastada no momento da aplicabilidade no ordenamento jurídico brasileiro, no instante em que deixa de ser apenas um texto legal e passa a ser produto de interpretação, ainda que a norma tenha preenchido seus requisitos necessários e suficientes para que seja válida e aplicável. Isso porque, ela tem por finalidade reconhecer que a norma jurídica pode possuir inúmeras exceções não perceptíveis de antemão, atraindo a atenção de diversas áreas do conhecimento além da teoria do direito e da argumentação jurídica como, por exemplo, a lógica e a filosofia (CUNHA JÚNIOR, 2015).

O entendimento doutrinário conceitua derrotabilidade ou superabilidade das normas como uma teoria que esclarece a não aplicação de uma regra ou princípio em decorrência das especificidades do caso concreto, visto que, a não aplicação da norma se justifica em valores cujo peso é maior no caso específico do que o postulado da segurança jurídica. (CUNHA JúNIOR, 2015).

Entende-se que não é a norma em si que é derrotada, mas sim o enunciado normativo. Nesta seara, Cunha Júnior (2015) leciona que "a norma é o resultado da interpretação do texto, diante do caso concreto." e discorre ainda que "apesar da singularidade da expressão "derrotabilidade", na prática o fenômeno é cotidiano e diariamente verificável nas interpretações jurídicas empregadas nas controvérsias processuais"

Para Bernardes e Ferreira (2013) a derrotabilidade das normas "tem a ver com a não aplicação, total ou parcial, de certa norma jurídica, apesar de exteriorizados os pressupostos a partir dos quais se deveria aplica-la em condições normais. [...] Por outras palavras, como os órgãos que editam normas são incapazes de prever as infinitas circunstâncias que futuramente aparecerão no momento em que uma norma deva ser aplicada, as previsões normativas estão sempre abertas a uma lista de exceções (cláusulas a menos que) que podem derrotar os comandos inicialmente propostos pela autoridade normativa."

Nesse diapasão, realizado os primeiros apontamentos, a referida pesquisa, traz por objetivo abordar a aplicabilidade no ordenamento jurídico brasileiro e a flexibilidade que tal teoria pode causar na aplicação do texto legal caso haja exceções não esperadas, principalmente em relação a efetivação de um dos principais princípios que é dignidade da pessoa humana, visto que, o direito não observado em virtude da norma pode ser um dos direitos fundamentais, portanto, inerentes a todo ser humano. 


\title{
HERMENÊUTICA JURÍDICA
}

A hermenêutica jurídica é o campo da Teoria Geral do Direito que se dedica ao estudo e desenvolvimento de princípio e métodos da atividade de interpretação, investiga as leis do pensamento e da linguagem e classifica os seus acontecimentos e consequências, buscando solidificar bases racionais e seguras para interpretação coerente das normas e demais textos legais (ALVES, 2019). Na área jurídica, a hermenêutica forma as regras e métodos para interpretação das normas, fazendo com que elas sejam divulgadas com seu sentido e alcance, determinando métodos para o entendimento legal, sendo considerada como um sistema humanístico de pesquisa (ALVES, 2019).

O termo "hermenêutica", deriva do grego hermeneuein, tomando inúmeros significados ao longo da história, sendo mais usualmente traduzida para interpretar. Deste modo, tem-se que esta é "um domínio teórico, especulativo, cujo objeto é a formulação, o estudo e a sistematização dos princípios e regras de interpretação do direito" (BARROSO, 2009a; SOARES, 2018). Em outras palavras, pode se dizer que ela, busca adequar enunciados já estabelecidos no caso concreto, afastando todas as ambiguidades, lacunas, imperfeições e má redação. Acrescenta Soares:

\begin{abstract}
A hermenêutica é, seguramente, um tema essencial para o conhecimento. Tudo que é apreendido e representado pelo sujeito cognoscente depende de práticas interpretativas. Como o mundo vem à consciência pela palavra, e a linguagem é já a primeira interpretação, a hermenêutica torna-se inseparável da própria vida humana (SOARES, 2018, p. 24).
\end{abstract}

A hermenêutica tem por finalidade o estudo e a sistematização dos processos aplicáveis para determinar o sentido e o alcance das expressões do direito. Luis Roberto Barroso (2009b) afere que "a hermenêutica é um domínio teórico, especulativo, cujo objeto é a formulação, o estudo e a sistematização dos princípios e regras de interpretação do direito".

O fato é que a hermenêutica é de contumaz importância para os operadores do direito, visto que, a aplicação desse mecanismo interpretativo possibilidade retirar o sentido objetivamente válido e determinar seus alcançes, desmistificando seu real conteúdo através da consideração dos sujeitos envolvidos e da situação fática do caso (ALVES, 2019). A hermenêutica não auxilia somente na interpretação, mas também na aplicação e integração do direito como um todo, garantindo que este se mantenha dinâmico na sociedade atual e que se atente as efetivas necessidades sociais que reclamam por sua aplicação, podendo ainda reconhecer a flexibilidade e maleabilidade das normas a ponto de ser interpretado de forma variável, desde que razoável (VASCONCELLOS, 2009).

Conhecer o direito material não é suficiente, visto que as leis precisam ser interpretadas de forma mais incisiva e aplicadas conforme as necessidades do mundo atual, cabendo ao aplicador estabelecer um paralelo entre a realidade jurídica e a fática, enquadrando o caso concreto à norma jurídica adequada, encontrando a melhor forma de amparar juridicamente os interesses humanos. (VASCONCELLOS, 2009). 


\section{A SINGULARIDADE DA INTERPRETAÇÃO DO DIREITO}

Em ato contínuo, como é perceptível o papel mais importante no âmbito da hermenêutica é a delimitação dos caracteres da interpretação do direito, visando apurar os aspectos singulares, através de uma análise do operador do direito que passa a enxergar o ordenamento jurídico como "uma viva e operante concatenação produtiva, como um organismo em perene movimento" que deve se moldar com a situação casuística e atual coerência observando as circunstâncias da sociedade (SOARES, 2018).

A interpretação não pode se limitar a reconhecer o significado da norma em abstrato, mas sim integrar a norma à realidade social, preservando a ordem e evitando os conflitos de interesse, na busca pela reconstrução do significado se baseando num conjunto de valorações (SOARES, 2018). A lei faz mais do que regulamentar determinada situação jurídica ou tutelar certo sujeito de direito, resgata-se seu valor e importância na sociedade, trazendo a noção indispensável de integração social, abrindo-se novas dimensões do nosso ser-no-mundo, porquanto a linguagem faz mais do que apenas descrever a realidade, revela um novo horizonte para a experiencia humana (CRUZ; LEITE, 2020).

Para Emilio Betti (1956) citado por Soares (2018), o processo interpretativo é uma tríade composta por: o espírito vivente e pensante do intérprete, uma espiritualidade que se encontra objetivada em uma forma representativa e a própria forma representativa. A tarefa de interpretar que diz respeito ao jurista não se esgota com o voltar a conhecer uma manifestação do pensamento, mas busca também integrar a realidade social em relação com a ordem e a composição preventiva dos conflitos de interesses previsíveis (CRUZ; LEITE, 2020).

Assim, a depender da referência hermenêutica tomada, a interpretação do direito modulará a própria expressão do discurso jurídico, valorizando a ordem, com a adoção do subjetivismo, ou a mudança, quando iluminada pelo objetivismo, aumentando a eficácia comunicativa do direito, que é uma linguagem do poder e de controle social. A interpretação histórica tem por escopo integrar de forma coerente a forma representativa com o pensamento que expressa, enquanto que a intepretação jurídica vai-se além, já que a norma não se esgota na sua primeira formulação, tendo vigor atual em relação com o ordenamento de que forma parte integrante e está destinada a permanecer e mudar a vida social (BETTI, 1956 citado por SOARES, 2018).

\section{DIREITO E LINGUAGEM}

O direito é produzido e aplicado a partir da linguagem. A partir de tal afirmação é preciso entender que o direito cria suas próprias realidades, ou seja, é a criação através do uso da linguagem com a finalidade de orientar os destinatários e operadores do direito, preservando o propósito maior do direito que é a regulamentação das condutas intersubjetivas (VASCONCELLOS, 2009). Genericamente tanto os debates políticos que dão origem ao material a ser normatizado, quanto a atuação da Assembleia Constituinte ao votar sobre determinada lei, quanto o dia o dia da aplicabilidade do direito tem a presença constante da linguagem para regular e orientar toda e qualquer comunicação jurídica (SOARES, 2018).

Frente ao direito positivado, o aplicador tem a atribuição de interpretá-lo, considerando as problemáticas que possam advir dessa interpretação como os vácuos jurídicos, a ambiguidade da norma e os inúmeros outros fatores linguísticos ENCICLOPÉDIA BIOSFERA, Centro Científico Conhecer - Jandaia-GO, v. 18 n.36; p. 77 2021 
que possui ligação direta na compreensão, na formação das convicções sobre o ordenamento jurídico e influência no caso concreto. O direito positivo decorre da linguagem, que é a transformação promovida em leis, sentenças, acórdãos, portarias, dentre outros (VASCONCELLOS, 2009).

Nesse sentido, pode se dizer que ver o direito como linguagem oferece aos destinatários das normas mecanismos capazes de auxiliar na investigação dos fenômenos jurídicos de forma detalhada, sendo a linguagem dividida em três planos: o plano da sintaxe, relativo ao estudo da estrutura formal da linguagem por meio de análises lógico-linguísticas; o plano da semântica, que tem por objeto averiguar o sentido das proposições; e o plano da pragmática, cuja finalidade é investigar o uso das preferências linguísticas (ROBLES, 1988; VASCONCELOS, 2009).

Não é possível, fazer uso indiscriminado da linguagem jurídica normativa, de modo que os operadores do direito não podem almejar somente um resultado interpretativo que satisfaça as suas pretensões pessoais, até porque a hermenêutica é essencialmente um fenômeno social devendo alcançar um nível relevante de compreensão e aceitação da sociedade (VASCONCELLOS, 2009).

Partindo do princípio de que o direito é de interesse da sociedade de forma generalizada, as linguagens dos textos legais precisam manter um mínimo de compreensibilidade principalmente ao tratar de aspectos e termos técnicos utilizados, apoiando o diálogo na linguagem comum para que os destinatários, que são muitas vezes leigos, compreendam o conteúdo, podendo guiar-se e aceitar as determinações (SOARES, 2018). Para que as normas tenham maior eficácia e para evitar que o indivíduo não alegue que deixou de cumprir a lei por desconhecimento da mesma, é preciso garantir que as normas sejam precisas, claras e concisas, pois somente assim é que se pode falar em segurança jurídica. Sendo assim, a linguagem pode ser vista como começo e limite, meio para um fim na qual a intermediação torna-se indispensável (VASCONCELLOS, 2009).

\section{INTERAÇÃO ENTRE INTERPRETAÇÃO E APLICAÇÃO DO DIREITO}

Sobre a aplicação do direito, pode-se considerar que o pensamento jurídico é determinado como pensamento ligado a normas e visando a aplicação, sendo que o caso jurídico é que determina o mecanismo utilizado. Frente a isso, os operadores do direito se preocupam em como os direitos serão positivados, por quem e de que maneira (VASCONCELLOS, 2009).

Canotilho (1993) defende que o texto legal somente adquire real normatividade quando transmutada em norma de decisão ou quando há solução de casos concretos, sendo imprescindível a atitude dos operadores porque são esses que confrontam a norma com a realidade, buscando validar a efetividade e potencialidade (VASCONCELLOS, 2009). Segundo o magistério de Alberto Jorge Junior (2004) citado por Soares (2018) pode-se dizer que as cláusulas gerais funcionam no interior dos sistemas jurídicos, mormente os codificados como elementos de conexão entre as normas rígidas (pontuais) e a necessidade de mudança de conteúdo de determinados valores, em meio a um ambiente social em transformação, operando, dentro de certos limites, a adaptação do sistema jurídico (aberto) às novas exigências na interpretação desses valores.

A evidenciação do caso concreto e a integração dos casos fatídicos são características da nova hermenêutica jurídica, isso porque, leva à impossibilidade de se "(...) isolar a norma da 'realidade"', pois esta, ao ser afetada pelo texto legislativo, transforma-se no "elemento material constitutivo da própria norma" (BONAVIDES, 
2005 citado por VASCONCELLOS, 2009). É necessário distinguir texto de norma e norma jurídica, para dividir o texto positivado como criação do legislador e a norma jurídica como produto da positivação do direito. Essa diferenciação, portanto, não configura a perda de força do direito positivo e sim sua preservação com o reconhecimento de que o mesmo, é o princípio e a delimitação das atividades interpretativas sem diminuir o potencial da interpretação e o papel do operador no processo de positivação (VASCONCELLOS, 2009).

\section{DA TEORIA DA DERROTABILIDADE DAS NORMAS HISTÓRICO}

A ideia de Derrotabilidade foi introduzida pela primeira vez na filosofia do direito por Herbert Lionel Adolphus Hart, jurista e filósofo inglês, em 1948, em seu ensaio denominado "The Ascription of Responsability and Rights", onde ele aduz que a Derrotabilidade é um fenômeno jurídico caracterizado pela expressão "a menos que". Segundo a original ideia de Hart, "quando o estudante aprende que na lei inglesa existem condições positivas exigidas para a existência de um contrato válido, ele ainda tem que aprender o que pode derrotar a reivindicação de que há um contrato válido, mesmo quando todas essas condições são satisfeitas" (HART, 1948, citado por VASCONCELLOS, 2009).

Levando em consideração a concepção hartiana, a derrotabilidade assume a inviabilidade de se elencar as condições necessárias e hábeis para execução do direito, visto que somente seria concebível relacionar suas condições normais ou típicas, que deveriam incluir de forma quase obrigatória uma ressalva denominada pelo termo "a menos que...", mantem relação às ressalvas que não poderiam ser previstas, e caso viessem a ocorrer, teriam a prerrogativa de abater a regra geral (RAASCH, 2020). Para Bernardes e Ferreira (2013, p. 245) sintetizando as características principais da Derrotabilidade das Normas ou Superabilidade tem-se que "a teoria da derrotabilidade normativa parte da premissa segundo a qual as normas jurídicas baseiam-se em raciocínios cujas justificativas podem ser 'derrotadas' diante da exteriorização de circunstâncias anormais, que não foram consideradas na formulação normativa."

Nesse sentido, Giorgio Pino (2010) afere que a ideia de derrotabilidade conecta-se com a ideia de exceção no sentido de que uma norma, seja regra ou princípio, é derrotável se, embora abstratamente aplicável, ela deixe de ser aplicada em razão da presença de alguma condição que a derrote no caso específico. Do mesmo modo, Fernando Andreoni Vasconcellos (2009), reconhece a falibilidade de toda norma jurídica, afirmando que, quanto maior o grau de abstração, maior é a chance de isso acontecer, bem como afirma que todo enunciado normativo pode ser reconduzido à formulação hipotético-condicional, ou seja, até um princípio pode ser derrotado a partir da lógica clássica.

A veracidade das proposições jurídicas pode ser rebatida não apenas pela negação dos fatos, mas também por alegação afirmando que, apesar da ocorrência dos fatos que levariam a consequência jurídico-normativa prevista na regra, existem outras circunstâncias relevantes que colocam o caso em uma linha de exceção que tanto pode derrotar quanto reduzir a alegação inicial. (VASCONCELLOS, 2009). Tal concepção explica os limites normativos do Direito enquanto guia de conduta frente aos casos difíceis, nos quais o aplicador do direito se depara com limites e circunstâncias não previstas que dão causas às exceções (RAASCH, 2020). 
A Derrotabilidade ocorre em relação às normas jurídicas e não ao texto legal, já que tal fenômeno nada mais é do que o abandono do texto legal em decorrência de circunstâncias excepcionalíssimas verificadas através de uma interpretação, somente sendo permitida a aplicação efetiva através da hermenêutica, pois esta retiraria da norma suas determinações, aplicando no caso concreto (RAASCH, 2020).

\section{DISTINÇÃO CLÁSSICA ENTRE REGRAS E PRINCÍPIOS}

Necessário é realizar a distinção entre regras e princípios, tendo as regras como normas que estão ou não em conformidade, obedecendo a um mandamento definitivo e os princípios que podem ser cumpridos em graus diferenciados e, portanto, podem ser sempre otimizados (BACKER, 2011).

Alexy (2003) apresenta em sua teoria um critério para realizar a distinção. $O$ critério, originalmente elaborado em seus primeiros escritos sobre a teoria dos princípios, parte não da noção de "derrotabilidade" mas da noção de "ser cumprido". Alexy (2003) entende as regras como normas que ou estão ou não estão em conformidade com, e, por isso mesmo, "são sempre ou satisfeitas ou não satisfeitas". Por outro lado, ele define os princípios como normas que podem ser cumpridas em diferentes graus: princípios, segundo ele, "podem ser satisfeitos em graus variados". Devido a essa diferença, Alexy (2003) considera as regras como mandamentos definitivos, em oposição aos princípios, que são mandamentos de otimização. De acordo com essa diferenciação, as regras, quando cumpridas, o são de forma absoluta, enquanto o cumprimento dos princípios é gradual. (ALEXY, 2003 citado por BACKER, 2011).

Nesse viés, pode se dizer que são considerados espécies de normas, ou seja, por estarem unidos às regras, integram o sistema normativo, de forma que o legislador ao conceber a norma, o magistrado ao efetuá-la e o operador do direito ao aprendê-la, deve considerar o caso definido, para que só então, delibere-se sobre o tipo de decisão mais adequada. (VASCONCELLOS, 2009). Tratam-se um direcionamento, uma opinião ou até mesmo o modo de ver algo, também pode ser reconhecido como um código de conduta, quando uma pessoa busca seguir, um alicerce em que alguém firma suas ações, seja para consigo ou perante a sociedade. Inclusive, como sendo algo abstrato, impalpável, não positivado, mas, que faz parte do subconsciente como algo preexistente (DINIZ, 1998, p. 29; LORENZETTI, 1998, p. 312).

Bernardes e Ferreira (2013) apontam preliminarmente que "pode-se concluir que somente os princípios são normas derrotáveis, pois qualquer regra comporta a prévia e completa enunciação de todas as respectivas exceções e hipóteses nas quais não se aplique" (BERNARDES; FERREIRA , 2013 citado por RAASCH, 2020).

Os princípios são a base do ordenamento jurídico brasileiro, norteando a sociedade e trazendo garantias para o meio social, auxiliando as pessoas nas interpretações das leis e impondo ao ser humano normas claras, possibilitando o conhecimento da aplicação e eficácia (ALEXANDRINO; PAULO, 2010).

Notoriamente os princípios devem intervir de forma fundamental para o justo equilíbrio das relações humanas, pois são através destes que ocorrem as criações das regras levadas a sociedade, identificando assim o verdadeiro objetivo e sentido da lei. (SOARES, 2018). A exposição dos princípios adentro de um sistema, tem como adequação primordial $\mathrm{o}$ ato de conhecimento, pois para conhecer um determinado sistema jurídico, deve-se identificar aqueles princípios que os ENCICLOPÉDIA BIOSFERA, Centro Científico Conhecer - Jandaia-GO, v. 18 n. $36 ;$ p. 80 2021 
estabelecem, propriamente pelo fato de cada norma ser aplicada a cada caso, dos quais os princípios interlaçam em seus estipulados âmbitos, acarretando dessa forma, verdadeiras normas jurídicas (ALEXANDRINO; PAULO, 2010).

Os princípios apresentam uma tríplice função. A primeira, a função interpretativa, da qual é um elemento de apoio. Segunda, a função de elaboração da norma, já que auxiliam o legislador. Terceira, a função de aplicação do direito, na medida em que servem de base para o juiz sentenciar (NASCIMENTO, 2009). Para Jan-Reinard Sieckmann e Aulis Aarnio (1990) citados por Backer (2011) a distinção clássica não é convincente, pois afirmam que princípios são mandamentos de otimizar e que estes podem ser satisfeitos tanto de forma completa quanto não ser satisfeitos de modo algum, sendo mandamentos definitivos com caráter de regras.

Quanto a Derrotabilidade, está, deve ser entendida como capacidade de acomodar exceções, contudo, estas não podem ser enumeradas em consequência da imensidão de circunstâncias que advém de casos futuros e que são desconhecidas (BACKER, 2011). A derrotabilidade tem origem na limitação humana em prever todas as circunstâncias relevantes e, por conseguinte, da correspondente deficiência estrutural das regras. Se as condições de uma regra são satisfeitas, então a conclusão se segue, a menos que ocorra uma exceção. Uma vez que não é possível prever todas as exceções, não é possível criar uma regra sem exceções. As regras simplesmente ordenam que algo seja feito sob determinadas condições (BACKER, 2011).

Os princípios, ao contrário das regras, não podem ter exceções, uma vez que o fato de todas as circunstâncias dadas serem consideradas sempre e a cada vez que um princípio é aplicado constitui parte de sua estrutura, obedecendo sempre um mandamento para otimizar (AMORIM, 2018). Se forem consideradas relevantes todas as circunstâncias, não pode haver exceções. Ao aplicar uma regra não é necessário levar em consideração todas as circunstâncias relevantes. Se a condição é satisfeita, segue-se a conclusão (BACKER, 2011).

A exigência de uma regra é a reunião complexa de circunstâncias das quais o resultado se mostra, independente de outras exigências que não mantem pertinência com as condições. A regra é derrubada, devendo ser amplamente revisada (MARINS, 2018). Não havendo conhecimento de todas as circunstâncias referentes ao presente e futuro, para que haja a aplicação dos princípios é suficiente a existência do maior número possível de circunstâncias relevantes, o que pode ser considerado, como prolongamento das possibilidades fáticas e jurídicas. A razão principal para a Derrotabilidade das regras é a incapacidade humana de prever todas as circunstâncias para aplicação dos princípios (VASCONCELLOS, 2009).

Existem impugnações referentes ao argumento de que regras e princípios podem ser diferenciados através da noção da Derrotabilidade. Tais objeções de inúmeros estudiosos têm comum o fato de que entendem os princípios como derrotáveis (BACKER, 2011). Feita a distinção entre regras como normas derrotáveis e princípios como normas não-derrotáveis, há uma explicação para a distinção entre o caráter prima facie das regras e dos princípios. As regras exibem um caráter prima facie, pois é sempre "possível incorporar ao caso uma exceção". Os princípios exibem um caráter prima facie diferente: são mandamentos prima facie porque "não possuem recursos que permitam determinar sua própria extensão" (BACKER, 2011).

Entende-se que o ordenamento jurídico é incapaz de resolver todos os conflitos judiciais de forma efetiva e que as normas estabelecidas quando aplicadas ENCICLOPÉDIA BIOSFERA, Centro Científico Conhecer - Jandaia-GO, v.18 n.36; p. 81 
em situações concretas podem incorrer em injustiças se diversa da finalidade inicial (ALVES, 2019). A superabilidade das normas surge então como mecanismo efetivo para resolver a antinomia, no intento de aplicar a norma jurídica no caso contrato evitando o surgimento de injustiças, e em casos de clara inconstitucionalidade da norma ou situação excepcional não prevista (BACKER, 2011). Nesse ínterim, a Derrotabilidade normativa é aplicável no ordenamento jurídico como instrumento de exceção, possibilitando que seja inserida no cotidiano jurisdicional, bem como possibilitando que as decisões judiciais estejam mais próximas dos ideais de justiça (MARINS, 2018).

\section{DERROTABILIDADE DO TEXTO OU DA NORMA JURÍDICA}

A derrotabilidade diz respeito a normas jurídicas e não a textos inclusos no direito positivo. Não há similitude entre texto de norma e norma jurídica, de modo que o processo de positivação de direitos será feito por ato do intérprete e operador e não do legislador, circunstância que divide a problemática jurídica em termos de produção e aplicação/interpretação (AMORIM, 2018). Para a doutrina moderna, o texto normativo e a norma jurídica não são a mesma coisa. Isso significa que de um mesmo texto podem ser extraídas diferentes normas, bem como uma mesma norma pode ser criada a partir de mais de um enunciado legal.

"As normas, portanto, resultam da interpretação. E o ordenamento,
no seu valor histórico-concreto, é um conjunto de interpretações, isto
é, conjunto de normas. O conjunto das disposições (textos,
enunciados) é apenas ordenamento em potência, um conjunto de
possibilidade de interpretação, um conjunto de normas potenciais. O
significado (isto é, a norma) é o resultado da tarefa interpretativa
(GRAU, 2006, p. 85)."

Tem-se que um mesmo texto pode servir tanto de fundamento para inúmeras normas jurídicas, ao passo que uma norma jurídica pode ser criada a partir de diversas mensagens legislativas. Isso porque, no instante em que se fala da aplicação do direito, do entendimento tido pelos intérpretes, quando o texto deixa de ser apenas texto e passa a integrar o mundo das interpretações, daí se torna possível o discurso da derrotabilidade (GAVIÃO FILHO;PREVEDELLO, 2019).

As normas jurídicas são a concretização dos valores sociais, coletados e positivados pelo legislador. São o ponto de vista segundo o qual as civilizações são caracterizadas por regras. Estas são de "dever ser" da coletividade. Os "deveres" limitam as ações dos homens uns com os outros. A norma veio para garantir bemestar, proteger o homem de seu próximo, das atrocidades que podem ser cometidas uns contra os outros (BOBBIO, 2016 citado por AMORIM, 2018).

A interpretação, ainda que esteja inserida em uma linguagem lógica, no momento em que ocorre, a derrotabilidade tem lugar exatamente dentro de um plano semântico-pragmático. (VASCONCELLOS, 2009). Pensando conforme a nãoidentidade entre texto de norma e norma, Riccardo Guastini afirma que, "às vezes, concorda-se que o texto normativo T exprime a norma N1, mas alguns se perguntam se tal norma é, ou não, 'falível' (derrotável), ou seja, sujeita a exceções implícitas que não podem ser identificadas a priori (GUASTINI, 2005 citado por VASCONCELLOS, 2009). 
Estando isso claro, pode-se afirmar que a derrotabilidade recai não sobre os textos que compõem o direito positivo, e sim sobre as normas jurídicas que são extraídas deles pelos intérpretes e aplicadores. Como bem expõe Fernando Andreoni Vasconcellos (2009, p. 53), “(...) a representação lógica da derrotabilidade encontra-se (e mantém-se) no plano sintático, no qual a derrotabilidade não acontece, mas apenas é representada, em um suporte físico".

\section{REGRA, PRINCÍPIOS E ESTRUTURA NORMATIVA}

Um sistema jurídico não pode ser constituído apenas por princípios, ou somente por regras, eis que se composto apenas por princípios tornar-se-ia excessivamente flexível, frente à ausência de regras claras de comportamento, ocasionando problemas de coordenação, conhecimento, custos e controle de poder (SOARES, 2018). Um sistema composto apenas por regras, aplicadas de modo formalista, seria absolutamente rígido, pela ausência de abertura para a acomodação das soluções às particularidades dos casos concretos (MARINS, 2018).

Diante disso, tem-se que os princípios não são mais importantes do que as regras, nem as regras são mais necessárias que os princípios, desempenhando, cada um, funções diferentes e complementares, não se podendo, então, conceber uma sem existir a outra. Em suma, regras e princípios são espécies de normas jurídicas que, enquanto referências para 0 intérprete, não guardam, entre si, hierarquia (MARINS, 2018).

A distinção entre regras e princípios seria lógica ou qualitativa, em que as regras seriam razões definitivas, possuindo uma determinação da extensão do seu conteúdo no âmbito das possibilidades jurídicas e fáticas, devendo ser excepcionadas em casos extraordinários através da cláusula de exceção "a menos que". Enquanto os princípios seriam razões prima facie que não contém um mandamento definitivo, mas sim, mandamentos a serem otimizados (ALEXY, 2003 citado por MARINS, 2018).

Há a afirmativa dos autores que as regras, por terem mandamentos concretos, no caso de colidirem seriam plenamente derrotáveis através da inserção de uma cláusula de ressalva/exceção. Os princípios, por outro lado, não seriam derrotáveis, já que não possuem mandamentos concretos, mas sim mandamentos de aperfeiçoamento. Assim, quando divergentes deveriam ser examinados e aperfeiçoados, prevalecendo ou não no caso concreto $(\mathrm{RAACH}, 2020)$. Frente a isso, tem-se que aplicabilidade da derrotabilidade da norma depende que a interpretação não viole ou infrinja qualquer finalidade atinente a norma ou postulado da segurança jurídica (CUNHA JÚNIOR, 2015).

\section{PANORAMA ATUAL DA TEORIA DA DERROTABILIDADE}

Em relação a derrotabilidade ("defeasibility"), está sugere que nem sempre o determinado por uma norma isolada será condizente com a exigência do caso fatídico no sistema do ordenamento jurídico e está se dá em razão dos limites extensivos e intensivos das normas positivadas para adequação eficaz do Direito e sua realização (MARINS, 2018). A normatização do ordenamento é sempre usada como critério para distinguir ou edificar uma exceção, sendo positiva quando tratar de forma explícita na própria norma e negativa quando houver critério de exceção aplicável de forma imediata, devendo ser atingido através de uma ponderação de normas jurídicas (MARINS, 2018). 
Nesta seara, é correto afirmar que a chave para a ideia de derrotabilidade é admitir a potencial capacidade dos intérpretes e aplicadores do direito de adicionar uma exceção "ad hoc" para normas existentes sem exceções, a fim de evitar uma conclusão jurídica abaixo do ideal, ineficiente, injusta, de resultado inaceitável juridicamente (SCHAUER, 1998 citado por MARINS, 2018). A derrotabilidade pertence essencialmente ao conceito de direito e de um sistema jurídico não defeituoso, de modo que dificulta a defesa da existência de um ordenamento completo, sem vácuos ou lacunas, para produzir conclusão jurídica justa (MARINS, 2018).

Onde tem-se a análise estrutural individual e separada da norma jurídica através da lógica "se A, então B", descrito pela lógica monotônica, opera-se de maneira prima facie. Por conseguinte, a interação dessas normas com outras do ordenamento jurídico resultando na impossibilidade de efetivação quando derrotada por outra norma em um caso específico ainda que tenha sido satisfeita, não haverá concretização sobre sua determinação (MARINS, 2018).

Dessa maneira, o texto legal funciona como previsão em que se pretende garantir um resultado perante fato eventual, contudo, a prática, dependerá de inúmeros fatores identificáveis no caso em particular. Atendendo a derrotabilidade a exigência de razão prática de modo a possibilitar a revisão da aplicabilidade das normas frente às especificidades do caso imprevisível, o legislador não poderia antever todos os fatos futuros que surgiriam com a evolução social. (VASCONCELLOS, 2009).

Dessarte, para simplificar a inclusão da cláusula "a menos que" inserta pela derrotabilidade, no raciocínio não monotônico uma regra de inferência toma por base o princípio da prioridade das exceções, além de afirmações positivas e negativas (ALVES, 2019). O requisito material mais importante da derrotabilidade é a coerência do julgador ou órgão durante a decisão, o processo de inclusão da exceção à regra constitui o fenômeno da universalização, a partir do qual a decisão singular se torna paradigmática, referência e modelo às posteriores decisões de casos similares (VASCONCELLOS, 2009). Dessa forma, para os casos considerados menos complexos deve ser utilizada a subsunção para a interpretação, enquanto para os casos mais difíceis não se aplica o mesmo critério, mas deve-se avaliar todos os aspectos, buscando-se o melhor contexto e resolução (VASCONCELLOS, 2009).

Acerca desse contexto, tem-se que a interpretação de um caso concreto e a aplicação dos princípios e regras conflitantes deve ocorrer levando-se em consideração atribuição de pesos, a concordância prática e a proibição de excesso, de forma a garantir a igualdade, a razoabilidade e a proporcionalidade (ÁVILA, 2008).

\section{A APLICAÇÃO DO PRINCÍPIO DA DIGNIDADE HUMANA NA TEORIA DA DERROTABILIDADE}

Com o advento da modernidade, os sistemas jurídicos ocidentais passaram a reconhecer o ser humano como o centro e o fim do direito. Seguindo a valiosa lição kantiana, a pessoa é um fim em si mesmo, não podendo converter-se em instrumento para a realização de um eventual interesse. Essa tendência humanizadora, ganhou forma após a Segunda Guerra Mundial, solidificando-se com a consagração do princípio da dignidade da pessoa humana, erigindo à condição de 
valor supremo dos sistemas jurídicos de inspiração democrática, nas palavras de Soares (2018).

O Princípio da dignidade da pessoa humana encontra fundamento no artigo 1, III da CF/88, alcançando maior notoriedade, ou seja, a atenção nas situações existenciais, vindo a existir tutelas jurídicas do homem voltadas à sua qualidade humana. No mais, este preza o indivíduo pelo ser pessoa, ou seja, deve proteger sempre a vida e a integridade enquanto sujeitos de direitos e deveres (MOREIRA et al., 2017).

Nesse sentido, oportuna é a lição de Flávia Piovesan (2000) citada por Soares (2018) ao destacar a essencialidade deste princípio, quando salienta que a dignidade da pessoa humana está erigida como princípio matriz da Constituição, imprimindo-Ihe unidade de sentido, condicionando a interpretação das normas e revelando-se, ao lado dos direitos e garantias fundamentais, como cânone constitucional que incorpora as exigências de justiça e dos valores éticos, conferindo suporte axiológico a todo o sistema jurídico brasileiro.

De maneira geral, sobre o referido princípio é importante destacar que essa valoração ocorre pelo fato deste princípio ser indispensável para unificar os direitos fundamentais com os fundamentos assumidos pelo Estado Democrático de Direito, logo, pode se dizer que esse princípio é fonte direta do conteúdo dos direitos fundamentais, sejam: coletivos ou individuais, de modo que "sem liberdades (negativas e positivas) não haverá dignidade, ou, pelo menos, esta não estará sendo reconhecida e assegurada" (SARLET, 2001; MOREIRA et al., 2017).

Em outras palavras, percebe-se que a dignidade assume a função primordial de equilibrar e evitar quaisquer tipos de discriminação nas relações jurídicas e interpessoais, todavia, vale lembrar que os mesmos devem sofrer algumas restrições, seja porque o Estado não tem condições de atendê-los em amplitude ou mesmo porque a efetivação acaba colidindo com outros direitos fundamentais (MOREIRA et al., 2017).

O fato é que frente a realidade e o contexto em que as partes estão envolvidas caberá ao magistrado fazer essa mediação e analisar qual dos direitos em questão deverá ser aplicado em detrimento do outro, uma vez que o que se busca é a justiça e não o cumprimento de todos os direitos sem qualquer observância (VASCONCELLOS, 2009).

Sobre o tema proposto, o referido princípio, independentemente de ser trazido como regra ou princípio, sempre deverá ser realizado um juízo de ponderamento e observar três critérios a saber: o primeiro, é a norma que exclui a outra, e, por isso, o dito princípio agiria no caso em concreto de forma hibrida; o segundo, é que se for visto o tal princípio como regra será aplicado de forma imediata e se enquanto princípio de fato, se dará de forma gradual (ALEXY, 2006, p. 87). Se aplicado o princípio em tela o conflito será resolvido, visto que, seja qual for a natureza do processo, a resolução deste é o objetivo central. No mais, seja qual for o princípio adotado, este sempre sofrerá limitações e será adequado ao caso em concreto sem prejuízo da verdade dos fatos (ALEXY, 2006, p. 87). 


\section{CONSIDERAÇÕES FINAIS}

O ordenamento jurídico é incapaz de responder a todos os conflitos judiciais de forma plena e eficaz, visto que a aplicação de normas estabelecidas em casos concretos pode acarretar em injustiças.

A derrotabilidade das normas jurídicas surge como hábil instrumento para resolver a antinomia, posto que objetiva deixar de aplicar uma norma jurídica em determinado caso concreto para evitar injustiças, bem como em casos de manifesta inconstitucionalidade da lei ou situação excepcional não prevista pelo Poder Legislativo.

Para garantir que as normas sejam aplicadas a situações diversas, alcançando sua finalidade e eficácia, é preciso que a interpretação mencionada seja feita de forma rigorosa e consistente, preservando a realização da hermenêutica jurídica.

Constatou-se, portanto, que a teoria em questão é aplicável no ordenamento jurídico como instrumento de exceção, sendo aplicado em última instância frente a indisponibilidade de outros meios, observando requisitos previamente estabelecidos e rigidamente descritos, sob pena da superabilidade ser instrumento para afastamento de dispositivos legais sem qualquer razoabilidade.

A derrotabilidade das normas jurídicas exige um aprofundamento maior no âmbito nacional, permitindo que seja inserida no cotidiano jurisdicional, bem como possibilitando que as decisões judiciais estejam mais próximas dos ideais de justiça.

\section{REFERÊNCIAS}

AARNIO, A. Las reglas en serio. In: Aarnio, Aulis; Garzón Valdés, Ernesto; Uusitalo, Jyrki (Comp.). La normatividad del derecho. Barcelona: Gedisa, 1997.

ALEXY, R.;On balancing and subsumption: a structural comparison. Ratio Juris, v.n.4. Oxford: Blackwell Publishing e University of Bologna, 2003.

. Teoria dos direitos fundamentais. Malheiros editores, $2^{\mathrm{a}}$ edição, trad. Virgílio Afonso da Silva, São Paulo, 2006.

ALEXANDRINO, M; PAULO, V. Direito administrativo. 18‥ ed, ver., Rio de Janeiro: Forense; Método, 2010.

ALVES, I. M. S. A hermenêutica jurídica como ciência interpretativa do mundo do direito. Jus.com.br. 2019. Disponível em: <https:/jus.com.br/artigos/74768/ahermeneutica-juridica-como-ciencia-interpretativa-do-mundo-do-direito> Acesso em 15 Mar 2020.

AMORIM, A. S. Ciência do direito, a interpretação normativa como a quarta dimensão do direito. Jus.com.br. 2018. Disponível em: < https://jus.com.br/artigos/66484/ciencia-do-direito-a-interpretacao-normativa-como-aquarta-dimensao-do-direito/3> Acesso em 15 Mar 2020.

ÁVILA, H. Teoria dos Princípios: da definição à aplicação dos princípios jurídicos. 8. Ed. ampl. e Atual. São Paulo: Malheiros, 2008. 
BACKER, C. Regras, princípios e derrotabilidade. Revista Brasileiro de Estudos Políticos. Belo Horizonte, 2011. Disponível em: < file://C:/Users/thais/OneDrive/\%C3\%81rea\%20de\%20Trabalho/127-

Texto\%20do\%20Artigo-1680-1-10-20180517.pdf> Acesso em 04 Jun 2021

BARROSO, L. R. Curso de direito constitucional contemporâneo. 2. ed. São Paulo: Saraiva, 2009a.

Saraiva, 2009b.

, Interpretação e aplicação da constituição. 7. ed. São Paulo:

BERNARDES, J. T; FERREIRA, O. A. V. A. Direito Constitucional: Tomo I, 3. Ed., Rev., Ampl. E Atual. Salvador: Juspodivm, 2013.

CANOTILHO, J. G. Direito Constitucional. 6. Ed. Coimbra: Livraria Almedina, 1993.

CUNHA JUNIOR, D. O que é derrotabilidade das normas jurídicas?. Brasil Jurídico, 2015. Disponível em <https://www.brasiljuridico.com.br/artigos/o-que-ederrotabilidade-das-normasjuridicas> Acesso em 29 Jun. 2020.

CRUZ, R. L. P.; LEITE, G. Hermenêutica Jurídica: Primeiras impressões. Jornal Jurid, 2020. Acesso em: 02/06/2021. Disponível em: < https://www.jornaljurid.com.br/colunas/gisele-leite/hermeneutica-juridica-primeirasimpressoes>

DINIZ, M. H. Dicionário Jurídico. v. 3. São Paulo: Saraiva. 1998.

GAVIÃO FILHO, A. P; PREVEDELLO, A. A noção de derrotabilidade para Herbert L.A. Hart. Revista Direito GV, 2019. DOI: htttp://dx.doi.org/10.1590/23176172201907

GRAU, E. R. Ensaio e discurso sobre a interpretação/aplicação do direito. 4. a ed. São Paulo: Malheiros, 2006.

GUASTINI, R. A Sceptical View on Legal Interpretation. In: COMANDUCCI, P.; GUASTINI, R. (coord). Analisi de diritto dicerche di giurisprudenza Analitica. Turim: Giappichelli, 2005.

HART, H. L. A. The Ascription of Responsability and Rights. Proceedings of the Aristotelian Society, New Series, Vol. 49 (1948-1949).

LORENZETTI, R. L. Fundamentos do direito privado. São Paulo, Revista dos Tribunais, 1998.

MARINS, S. Uma questão de derrotabilidade. E-publica. 2018. Disponível em: < https://e-

publica.pt/volumes/v5n1a11.html\#: :text=Enquanto\%20que\%20os\%20princ\%C3\%A Dpios\%20seriam,s\%C3\%A30\%20mandamentos\%20a\%20seres\%20otimizados.\&tex 
$\mathrm{t}=$ Assim\%2C\%20quando\%20colidentes\%20deveriam\%20ser,n\%C3\%A30\%20no\%2 0caso\%20espec\%C3\%ADfico18.> Acesso em 20 Jun 2020.

MOREIRA, A. L. B.; SOUZA, I. C.; BASTOS, R. R. Os direitos fundamentais e o princípio da dignidade da pessoa humana. In: Congresso Interdisciplinar-ISSN: 2595-7732. 2017. Disponível em: < http://anais.unievangelica.edu.br/index.php/cifaeg/article/view/618> Acesso em 29 Jun 2020.

NASCIMENTO, A. M. Curso de direito do trabalho: história e teoria geral do direito do trabalho: relações individuais e coletivas do trabalho. 24 ed. Ver. Atual e ampl. São Paulo: Saraiva 2009.

PINO, G. Neil MacCormick on interpretation, defeasibility, and the rule of law. Paper presented at the Conference Legal Reasoning and European Laws: The Perspective of Neil MacCormick, 21 mai/2010. Florença: European University Institute.

ROBLES, G. Las reglas del Derecho y las reglas de los juegos. 2. ed. México: UNAM, 1988.

SARLET, I. W. Dignidade da pessoa humana e direitos fundamentais na Constituição Federal de 1988. Porto Alegre: Livraria do Advogado, 2001.

SIECKMANN, J. R. Regelmodelle und Prinzipiensysteme des Rechtssystems. Baden-Baden: Nomos, 1990.

SOARES, R. M. F. Hermenêutica e interpretação jurídica. 4. Ed. São Paulo: Sairava, 2018.

VASCONCELLOS, F. A. O conceito de derrotabilidade normativa. Acervo digital, UFPR. $\quad$ Curitiba: 2009. Disponível em: < https://acervodigital.ufpr.br/bitstream/handle/1884/18639/O;jsessionid=5390B770F78 63F260158EEEA38782B15? sequence=1 > Acesso em 15 Mar 2020.

RAASCH, R. W. Teoria da Derrotabilidade (Defeasibility) das Normas. Âmbito Jurídico, 2020. Disponível em: https://ambitojuridico.com.br/cadernos/direitoconstitucional/teoria-da-derrotabilidade-defeasibility-das-normas/ Acesso em $15 \mathrm{Mar}$ 2020. 